Адрес статьи / To link this article: http://cat.ifmo.ru/ru/2018/v3-i3/153

\title{
Цифровая культура в сетевом обществе: социально-философский анализ
}

\author{
Е.Е. Елькина \\ Университет ИТМО, Россия \\ e.e.e.1@mail.ru
}

\begin{abstract}
Аннотация. Статья посвящена социально-философскому анализу становления сетевого общества и роли цифровой культуры как нормативно-этического регулятора социальных отношений в условиях глобализации и виртуализации социальных коммуникаций. Представлен анализ причин перехода информационного общества в сетевое в результате цифровой революции, развития Интернет и NBICS-конвергентных технологий, формирующих информационную инфраструктуру сетевого общества, способствующую виртуализации социальных коммуникаций. Рассматриваются положительные и отрицательные факторы влияния глобализирующихся социальных сетевых коммуникаций на формирование нового социального порядка, децентрализацию власти, формирование моделей и практик цифровой культуры. В статье представлен анализ понятия и основных подходов к исследованию цифровой культуры, рассматривается проблема интеграции практик цифровой культуры и традиционных форм культуры в становлении сетевого общества как условие стабильности социальной системы.
\end{abstract}

Ключевые слова: сетевое общество, Интернет, информационно-коммуникативные технологии, виртуальная реальность, дигитализация, цифровая культура, трансформация ценностей

\section{Введение}

Современное общество в результате цифровой революции и возрастающей роли Интернет в совершенствовании форм электронного обмена информацией для реализации различных видов деятельности переживает трансформацию сложившейся социальной структуры, моделей коммуникации, ценностных ориентаций, культурных практик. Указанные изменения свидетельствуют о формировании цифровой эпохи и становлении сетевого общества, приходящего на смену информационному. Динамика социальных изменений в экономической и политической сферах характеризует вступление современного человечества в период нестабильности, балансирование между хаосом и порядком.

Для социальной философии задача стоит не только в анализе происходящих изменений с учетом глобализации социальных коммуникаций, в критическом рассмотрении современных и футурологических моделей сетевого общества, но и в поиске ценностных императивов в сфере культуры, способных обеспечить устойчивое неравновесие сверхсложных социально- 
коммуникационных систем. С этой целью в статье представлен анализ существующих методологических подходов к исследованию цифровой культуры и сущности дигитализации процесса, лежащего в основе происходящих информационно-технологических и социокультурных изменений.

Для определения тенденций развития сетевого общества и цифровой культуры в статье рассматриваются практики цифровой культуры как новые формы социальных коммуникаций, ставится проблема механизмов интеграции цифровой культуры и культуры традиционной как основание нормативно-этических регулятивов взаимодействия социальных акторов в условиях эпохи перемен.

В качестве методологии исследования изменений в характере социальной системы в результате вступления информационного общества в новый (шестой) технологический уклад используются принципы социальной философии и деятельностного подхода. NBICSконвергентные технологии и глобальная сеть Интернет формируют принципиально иную информационно-технологическую инфраструктуру сетевых коммуникаций как основы общественного устройства.

Сравнительный анализ моделей сетевого общества, представленный в статье, опирается на принципы компаративистики. В определении тенденций развития сетевых коммуникаций используются идеи футурологов (Э. Тоффлера, Ф. Фукуямы и др.), философов, социологов, культурологов о критериях, определяющих качественные трансформации в развитии сетевого общества, а также положения социальной синергетики о роли идеалов в развитии самоорганизующихся систем (идеи В.П. Бранского и его школы).

В исследовании цифровой культуры автор исходит из двух основных направлений ее развития: технократического, в русле идей трансгуманистической эволюции, и социокультурного, представленного различными методологическими подходами к ее анализу. Развитие сетевого общества и цифровой культуры сопровождается изменением парадигм человека («одномерного человека» в обществе потребления - Г. Маркузе и др.), техночеловека (в информационном обществе), включая футурологические модели: многомерного человека, виртуального и постчеловека (клона, киборга, мутанта) [18], появление которых прогнозируется в результате комплексных изменений в развитии общества, технологий, способов коммуникаций.

\section{Становление и тенденции развития сетевого общества}

Современное информационное общество благодаря стремительному развитию Интернеткоммуникаций и их роли в глобализации и управлении ключевых сфер жизнедеятельности социальных систем (экономики, политики, науки, культуры) обретает черты сетевого общества. Его основные модели представлены в работах М. Кастельса, Я. ванн Дейка, Э. Тоффлера, Б. Латура, М. Каллона, Дж. Аркиллы, Д. Ронфельдта, Д. Барни и других.

Идеологи сетевого общества определили черты, отличающие сетевое общество от общества информационного: 1) наличие развитой цифровой инфраструктуры как основы интерактивных цифровых коммуникаций; 2) формирование и институционализация сетей как формы организации и взаимодействия социальных, политических, экономических ассоциаций внутри сетевого общества и за его пределами [22]; 3) власть медиа; 4) управление знаниями. По выражению Кастельса, «Именно сети составляют новую социальную морфологию наших обществ, a распространение сетевой логики в значительной мере сказывается на ходе и результатах процессов, связанных с производством, повседневной жизнью, культурой, властью» [11, с. 494]. Другим важным фактором сетевого общества становится виртуализация социальных коммуникаций, расширение киберпространства и сокращение до минимума времени (благодаря высокой скорости передачи сообщений) [23, p. 386-387].

Ведущую роль в становлении сетевого общества исследователи отводят Интернету. Глобализация интернет-коммуникаций трансформирует иерархическую структуру общественного устройства и формы государственного управления социальными процессами в гибридные формы контроля. Последние включают наряду с государственными структурами власти контроль межнациональных корпораций в сфере экономики, политики, бизнеса. Расширение сферы электронных форм социальных коммуникаций приводит к виртуализации идеологии, политики,

International Culture \& Technology Studies, Vol. 3, No. 3 
экономики. Противостояние реальных и виртуальных структур власти увеличивает напряженность в обществе, ведет к росту социальных конфликтов, к состоянию хаоса и нестабильности. Дж. Аркилла и Д. Ронфельдт в анализе сетевого общества обращают внимание на информационное неравенство и трансформацию конфликтов в кибервойны [2, с. 68-69].

Анализ принципов и форм сетевых коммуникаций в сфере бизнеса, политики и экономики широко обсуждается в отечественной и зарубежной литературе [7]. В отличие от жесткой иерархической системы социальных коммуникаций сети являются более гибким механизмом встраивания новых акторов и удаления неэффективных «узлов» для достижения поставленных целей $[11$, с. 495]. Сети кардинально революционизируют сферу экономики и бизнеса. Благодаря широкому доступу к сети Интернет и относительно дешевым каналам сетевых коммуникаций с высокой пропускной способностью передачи информации прогрессивные менеджеры не заинтересованы в сохранении устойчивых производственных коллективов, организуя сетевые корпорации, привлекая к сотрудничеству высокопрофессиональных исполнителей, независимо от страны их проживания. При различных конфигурациях сетевых коммуникаций (линейной, многоканальной, звездообразной [2, с. 69]) Интернет выполняет роль контролирующего центра, продвигающего интересы нетократии, формирующей вертикальные структуры сетевых коммуникаций.

Интернет становится посредником вовлечения людей в виртуальные сообщества, в пространство киберкультуры. Помимо индивидуальных форм коммуникации через электронную почту существуют различные формы коллективной коммуникации посредством телеконференций, интерактивных систем коллективной коммуникации (Internet Relay Chat) для проведения дискуссий, а также различные организационные ресурсы (on-line курсы, интернет-проекты, сетевые игровые сервисы [19, с.31].

Ванн Дейк исследует влияние сетевых коммуникаций в переходный период от массового общества к сетевому на индивидуальном, групповом и глобальном уровнях, их воздействие на изменение социальной среды (трансформацию ценностных установок, поведенческих моделей, причин социальных конфликтов) [25]. Влияние масс медиа на становление сетевого общества выражается в трансляции стереотипов массовой культуры и формировании клипового сознания. Интегрируя телекоммуникации и медиа среду в единое виртуальное пространство, Интернет становится публичной сферой, (неподконтрольной государству), для выражения политических предпочтений и ценностных ориентаций акторов сети, мобилизует интернет-сообщества для выполнения различных целей, формулируемых политическими лидерами и СМИ [10]. С одной стороны, социальные сети расширяют возможности социальных акторов в самореализации, с другой стороны, они усиливают контроль за действиями индивидов в сетях и концентрируют власть в руках ограниченной группы лиц, ограничивают степень человеческой свободы.

С расширением киберпространства и многообразием практик цифровой культуры возрастает роль этических регулятивов социальных коммуникаций, способных интегрировать цифровые формы культуры в сложившиеся формы культуры для достижения устойчивости социальной системы. В определении вектора развития глобализирующегося общества, согласно принципам социальной синергетики (В.П. Бранский и его школа), важную роль играет определение смысловых, этических, мировоззренческих ориентиров человечества (идеалов) [3, c.11-39]. При этом само общество следует рассматривать: а) как глобального антропологического субъекта в результате глобализации интернет-коммуникаций и б) с учетом многообразия национальных форм культуры, определяющих культурную идентичность социальных общностей планетарного человечества.

\section{Цифровая культура: теория и практики}

\section{Методологические подходы к анализу цифровой культуры}

Методологические подходы к анализу цифровой культуры отражают в ее понятии ценностные установки философов и представителей научного сообщества (гуманитарную или технократическую); анализ осуществляется на различных уровнях рефлексии процессов дигитализации в культуре (философский дискурс, общенаучный подход, междисциплинарное исследование, анализ различных практик цифровой культуры в художественной сфере, в 
образовании и др.). Среди многообразия методологических подходов к анализу цифровой культуры можно выделить две основные тенденции: гуманитарную и технократическую.

Технократический подход к анализу цифровой культуры представлен в историкосоциологических исследованиях, движении трансгуманизма, в футурологических проектах отечественных и зарубежных исследователей, в философском дискурсе отдельных авторов, в сфере проектирования NBICS-технологий.

Историко-социологический подход (Д. Белл, Э. Гидденс, Д. Нейсбит, М. Кастельс) сосредоточен на периодизации развития цифровой культуры в результате информационных революций. Представители данного подхода акцентируют внимание на роли цифровых технологий в изменении социальной структуры информационного общества, форм социальноправовой и политической культуры, на виртуализации социальных коммуникаций и практик как источниках трансформаций в культуре [23, p. 386-387].

В движении трансгуманизма, объединяющем разработчиков искусственного интеллекта, биотехнологов и философов технократической ориентации в России и на Западе, представлены такие его формы, как христианский трансгуманизм, демократический трансгуманизм, социалистический трансгуманизм, анархотрансгуманизм, постгендеризм, сингуляритаризм и др. [14, с. 57]. Представители данного направления выражают оптимизм в отношении будущего человечества и ратуют за свободу человека в выборе морфологических форм эволюционного развития: киборга, сверхчеловека, постчеловека $[14$, c. 57] и объединяющей роли киберкультуры.

В футурологических концепциях (А. Азимов, Э. Тоффлер, Ф. Фукуяма, М. Каку), анализ цифровой культуры опирается на идеи техноутопий с элементами научно-фантастической прозы, методологию прогнозирования научно-технологического развития как основу трансформаций природы человека и дигитализации общества и культуры, идеи социального проектирования и конструктивизма. В данном направлении рассматриваются различные проекты взаимодействия человеческого и искусственного интеллекта: от тотального контроля искусственным интеллектом человека до интеграции на основе партнерских отношений [24, с. 165-175].

Технократически ориентированный философский дискурс цифровой культуры, представленный в работах Р. Гира, Д.В. Галкина и др., согласно которому методология анализа цифровой культуры должна решить две задачи: определить предпосылки становления цифровой культуры и осуществить анализ ее ключевых феноменов (Интернет, видеоигры, персональный компьютер, системное программное обеспечение, новые медиа, системы виртуальной реальности и др.). Их реализация опирается на принципы технологического детерминизма, трансгуманизма, постструктурализма и медиа-археологии. В анализе развития цифровой культуры Р. Гир, один из основателей данного направления исследований, определяет дигитальность как маркер культуры информационного общества, включающий артефакты, означивания и коммуникации, отличающие современный образ жизни от других форм культуры [6]. Идеи Гира развивает Д.В. Галкин, определяя «единую цифровую культуру» как тотальность артефактов и символических структур, «основанных на цифровом кодировании и его универсальной технической реализации, тотально включенных в институциональную систему и способствующих поддержанию определенных ценностей, закрепленных ментально и создающих формы самодетерминации» [5, с. 16]. Ядром цифровой культуры, согласно данному исследователю, выступает «универсальный вычислительный автомат», обретающий на различных ее уровнях соответствующие культурные интерфейсы [5, с. 16].

В рамках гуманитарного подхода методология анализа цифровой культуры представляет различные уровни и цели исследования. Философский дискурс проблематики цифровой культуры (В.А. Кутырев, В.Э. Багдасарян, Д.Е. Прокудин, Е.Г. Соколов, Н.Л. Соколова) сосредоточен на мировоззренческих и онтологических вопросах в связи с расширением процессов дигитализации в культуре; сопровождающихся трансформацией ценностей, образов реальности, изменением характера коммуникаций и поведенческих моделей.

Понимание сути культуры очень важно в мировоззренческом отношении. Генезисом культуры являются метаструктуры, проявляющиеся в культуре и выступающие в качестве связующего звена человека и культуры, человека и мироздания. С точки зрения Н. Бердяева,

International Culture \& Technology Studies, Vol. 3, No. 3 
Вл. Соловьева, П. Флоренского, К. Ясперса, в основе исторического развития лежит культ, связь с высшим миром, благодаря которой осуществляется эволюционное развитие человечества и его переход на более высокую ступень (ноосферы, богочеловечества, трансцендентный уровень бытия). В соответствии с принципами гуманизма распространение понятия цифровой культуры на культуру в целом в методологическом и мировоззренческом отношениях недопустимо, ибо не может средство - технология (в т.ч., цифровая) лежать в основании Культуры и определять смысл эволюции человечества. Не все уровни Культуры подлежат дигитализации (сфера трансцендентного, духовного преображения человека). В силу утраты ориентира происходит исчерпание духовных потребностей и озабоченность повседневностью, стремление к доминированию и деструктивности. Нарушение техно-гуманитарного баланса в культуре ведет к тоталитаризму, войнам, концу Истории.

В рамках гуманитарного подхода цифровая культура определяется как:

- переход от аналоговых форм к цифровым форматам, сопровождающийся трансформацией иерархического строения культуры («ядро» - «периферия») в кластеризацию ее форм и сетевые коммуникации; ликвидацией «символического порядка» и установлением «порядка вещей» [15, с. 83-91];

- широкое поле артефактов и практик, появившихся благодаря цифровым технологиям (компьютерные игры, Интернет, технологическое искусство, гуманитарная информатика и др.), анализ которых позволяет определить специфику и предмет исследования цифровой культуры, а также процессы трансформации культуры в связи с распространением цифровых технологий. Н.Л. Соколова отмечает, что исследование влияния цифровых коммуникативных технологий на культуру вырастает в исследование взаимосвязанных и взаимодействующих между собой культур, цифровой и «не-цифровой», а также разных исследовательских парадигм, в частности, отечественной культурологи и британских Cultural Studies [16, с.8-9].

Уровневая структура цифровой культуры - недостаточно разработанный вопрос. По сути, анализ уровней цифровой культуры представляет исследование влияния интернета и конвергентных технологий (с учетом их амбивалентных трансформационных возможностей) на изменение идентичности человека, социальной реальности и культуры как жизненного мира современного человечества.

В качестве подуровней цифровой культуры можно выделить области социальных взаимодействий в сфере культуры как междисциплинарные практики в эпоху цифровой революции, включающие: научно-техническую цифровую культуру и коммуникации, политическую цифровую культуру, художественную цифровую культуру, правовую цифровую культуру, цифровую культуру в сфере образования.

Определение «оцифрованного человека», встречающееся в техно-дискурсе, требует анализа допустимых границ дигитализации культуры и человека. Данная проблема предполагает анализ вопросов:

- В чем суть дигитализации и какова ее роль в прогрессивном развитии / регрессе культуры?

- Есть ли у Истории цель и каковы современные стратегии достижения цели?

- $\quad$ В чем положительные и отрицательные воздействия цифровых технологий на развитие человека и цивилизации?

- B чем проявляется взаимосвязь различных уровней цифровой культуры?

В анализе данных вопросов следует ориентироваться на взаимосвязь «внутреннего» и «внешнего» факторов в исследовании природы человека и ее трансформации под воздействием цифровых технологий. Мир в качестве предметного представляется человеку благодаря процессам объективации языка, мышления, др. психических процессов, в основе которых лежит преобразование различного вида энергий в смысловые структуры, информацию, объекты реальности. Человек потенциально представляет собой многомерную модель, в которой количество проявленных уровней, отражающих ту или иную пространственно-временную 
мерность событий, на которых способен себя проявлять человек, определяется эволюцией мозга и полем его творческой активности [21, p. 113-117; 17, с. 254-269].

В чем суть дигитализации, лежащей в основе цифровой культуры? Дигитализация связана с развитием информационных технологий и Интернета. Слово «компьютер» переводится как «вычислитель» [20, с. 54], хотя современные компьютеры помимо вычислений выполняют широкий спектр операций под общим названием «искусственный интеллект». Суть дицитализации — в технизации времени, приближающей конец Истории.

Дигитализация кардинально изменяет модель культурного поведения человека и систему социальных взаимодействий в культуре. Интернет стирает границы между гипертекстом и контекстами, позволяет бесконечное расширение контекстов и опирается на сетевую логику. Опыт общения в виртуальной реальности трансформирует сложившиеся представления индивида о мире, художественном вымысле, взаимодействиях с другими людьми. Законы виртуальной реальности не тождественны законам физического мира, они адекватны логике машинных языков, воспроизводящих «конструктивную роль циклов как строительного материала функциональных процессов». Виртуальный опыт возвращает человека к циклической модели восприятия времени, характерной для мифологической культуры древних обществ. Способность адаптации к усвоению больших информационных массивов и интенсивности перемен для сохранения идентичности требует от человека повышения рефлексивности своей изменчивости [20, с. 58-59].

Наименее исследованной является проблема дигитализации как преобразование различного вида энергий при взаимодействии человека и сетевых устройств [17]. Передавая технике выполнение части своих функций (телесных, сенсорных, интеллектуальных) человек расплачивается тем, что постепенно становится придатком технологии. Оцифровка человека имеет целью ограничение человеческой свободы и представляет опасную тенденцию. Для ее преодоления необходимо воспитание потребностей в использовании продуктов цифровых технологий и культуры коммуникаций. Человечеству в очередной раз предстоит ответить на вызов, чтобы сохранить себя в качестве сообщества разумных людей. Для этого необходимо хранить преемственность оснований Культуры, обеспечивающих связь времен, объединяющих разнородные сферы общественной жизни и представляющих скрепы цивилизации.

\section{Практики цифровой культуры}

«Digital Humanities». Среди многообразных практик цифровой культуры наиболее перспективными являются «Digital Humanities» (Цифровые гуманитарные науки), «Art \& Science» (Искусство и наука), направления цифрового искусства.

Цифровые гуманитарные науки, (среди других определений - «электронные гуманитарные науки» / e-Humanities /, «цифровая информатика», «виртуальные исследовательские среды», «цифровые исследования в гуманитарных науках») представляют осуществление междисциплинарных проблемно ориентированных исследований на пересечении дисциплинарных границ гуманитарных и технических знаний в цифровой среде. Они объединяют теоретические и практические методы исследования с применением цифровых технологий.

В «Манифесте цифровых гуманитарных наук», опубликованном в 2010 г. профессором истории, директором Центра открытых электронных изданий (Франция), М. Дакос, данная область определяется как «неоднородная среда, матрица конвергентных практик, которые исследуют человечество и для которых распространение печатных источников не является единственной или нормативной средой для производства и / или распространения знания» [9, с. 93]. Появление новых парадигм в социально-гуманитарных науках, таких как вычислительная история, гуманитарная информатика, компьютерная лингвистика, киберпсихология и др., свидетельствует о переводе в цифровой формат тех областей гуманитарного знания, в которых применяются вычислительные технологии. Многообразие практик Digital Humanities на пересечении гуманитарных наук и информационно-коммуникативных технологий объясняется целями образования и исследовательскими задачами в определении контекстного знания (исторического, художественного, политического, социального) как источника новых знаний.

International Culture \& Technology Studies, Vol. 3, No. 3 
Еще одна область цифровых гуманитарных наук связана с оцифровкой коллекций изображений и управлений этими коллекциями, с использованием трехмерных моделей артефактов и их визуализацией (например, оцифровка коллекций музеев).

Двойственность воздействия Digital Humanities на сферу гуманитарного знания состоит в том, что с одной стороны, они представляют перспективные направления междисциплинарных исследований; формируют новые подходы в исследовании культурных артефактов и сфере образования; расширяют доступ к источникам информации и способствуют развитию международного сотрудничества ученых. Через создание электронных библиотек и электронных музеев осуществляется сохранность культурного наследия. С другой стороны, гуманитарное знание испытывает давление технодискурса и утрачивает свое предназначение: побуждать к творческому преображению жизни.

Цифровые практики в сфере образования. Применительно к практикам цифровой культуры в университетском сообществе цифровую культуру можно определить как «социокультурную реальность, в которой компьютеры, мультимедиа и интернет открывают новые формы восприятия природной, человеческой и общественной реальности» (О.В. Шлыкова) $[1$, c. 37]. Взаимовлияние информатизации, цифровой науки и новых направлений цифрового искусства формируют новые модели цифровой культуры, такие как Art \& Science, и осуществляют их трансляцию в образовательном процессе в качестве новых предметных курсов.

Практики цифровой культуры способствуют виртуализации образования, расширению сетевых форм коммуникации и интерактивных форм обучения. Воздействие электронной среды на человека усилено включением студентов и преподавателей в системы семантических сетей, Интернета, он-лайновых курсов, медийных интерактивных технологий как способов организации образовательного процесса, научно-исследовательской работы и организации досуга.

Электронная образовательная среда является источником трансформации образов «Я», отношений «Я» и «Другой». Виртуализация внутреннего измерения субъективного опыта под воздействием медиатизации продуцирует «симулякры», переживаемые как действительное. Геймификация, виртуализация и интерсубъективность в образовании конституируют новые интерактивные смысловые пространства, трансформируют мировоззренческие установки, включая установку на интеграцию естественного и искусственного интеллекта, и систему ценностей.

«Digital Art». Искусство в цифровую эпоху характеризуется влиянием кибернетического техно-дискурса и модернистского мировоззрения на формирование культурных практик, таких как «роботизированная скульптура», «алгоритмическая живопись», «компьютерная поэма», представляющих эстетический вызов традиционной «высокой» культуре. Многообразие оригинальных цифровых художественных практик, таких как виртуальная реальность, интерактивные инсталляции, net-art и др., представляющие авангардные течения к. XX-XXI вв., демонстрируют «радикально новую эстетику», гибридизацию искусства, науки, политики и технологий [4, с. 58-67].

Различные формы интеграции компьютерных технологий и художественных практик отразились в названии видов цифрового искусства: генеративное, эволюционное, фрактальное, традиционно-цифровое, видео-арт, цифровой дизайн, видео-инсталляция и др., в совокупности представляющих Digital Art. Е.И. Кириченко определяет цифровое искусство как «вид творческой деятельности, в которой произведения создаются и модифицируются при помощи языков программирования и компьютерных программ» [12]. Согласно С.В. Ерохину, цифровое искусство включает цифровые копии оригинальных произведений традиционных видов искусства, «псевдоцифровые», цифровые и гибридные формы [8, с. 20-21].

Важной особенностью цифрового искусства является его влияние на трансформацию структуры и природы творчества (художник - произведение - реципиент). В традиционном искусстве воплощение творческого замысла осуществлялось художником как выражение художественной идеи с использованием соответствующих технологий. Назначение искусства состояло в преображении человека. Теоретическая модель существования произведения цифрового искусства характеризуется тремя иными параметрами: наличием кода, сетевым пространством, интерактивностью (Л. Манович) [13, с. 355-356].

Культура и технологии, Том 3, № 3 
Благодаря Интернет-технологиям произведение цифрового искусства может создаваться не отдельным художником, а коллективом соавторов, включая художника, дизайнера, специалистов в области IT. Произведения цифровых форматов в силу своей коммуникативной функции расширяют аудиторию реципиентов. Обладая интерактивностью, они изменяют формирование культурного опыта. С помощью программного обеспечения 3D зрители способны виртуально «проникнуть» в сознание другого человека, испытать погружение в виртуальные компьютерные миры, дистанционно осуществить виртуальный тур по музею и т.п.

\section{Заключение}

1. Как показывает анализ, становление сетевого общества отражает его основные черты: возрастающее влияние Интернет и масс медиа на формирование институциональных сетевых структур социальных коммуникаций во всех сферах общественной жизни; наличие гибридных форм управления и политического контроля; виртуализацию социальных коммуникаций, возрастание политической напряженности и нестабильности.

2. В связи с формированием нового социального порядка необходимо прогнозирование развития сетевого общества с учетом критического анализа его моделей, влияния закона техногуманитарного баланса на устойчивость социальной системы: чем выше технологии - тем большим потенциалом должна обладать культура (обращение к традиционным формам культурных практик, поискам новых смыслов, сфере духовного творчества).

3. Как показывает анализ методологических подходов к исследованию цифровой культуры, она не представляет тотальной дигитализации, репрезентирует многообразие моделей, сформированных интеграцией цифровых технологий с не-цифровыми формами знаний и деятельности. Гуманитарная стратегия в развитии цифровой культуры объединяет представителей синергийной антропологии, исследователей отдельных концептуальных моделей и практик цифровой культуры, возникающих на пересечении традиционных форм культуры, компьютерных технологий и семиотических систем сетевого общества.

4. Развитие практик цифровой культуры, основанных на цифровых технологиях, свидетельствует о двойственности ее результатов на эволюцию человека и общества (как положительных, так и отрицательных в силу амбивалентности технологий). Дигитализация человека превращает его в придаток технологий искусственного интеллекта, тогда как потенциал возможностей многомерной парадигмы человека остается мало изученным.

5. Глубокие идеи, касающиеся законов ноосферной ступени развития планетарной цивилизации, были сформулированы представителями русского космизма, философами, учеными, поэтами. Мы обладаем уникальным философским наследием, но оно не востребовано современниками «цифрового» века.

6. В рамках цифровой культуры формируются новые формы нормативных и ценностных регулятивов социальных коммуникаций — цифровой этикет, этика сетевого общества.

\section{Литература}

[1] Алексеев А.Ю. Когнитивно-антропологические проблемы исследования электронной культуры // Вестник гуманитарного факультета ИГХТУ. 2014. Вып. 7. С. 35-40.

[2] Балаян А.А., Томин Л.В. Современные дискуссии о сетевых организациях и сетевом взаимодействии. Методология анализа и проблемы практического применения // Научные труды СЗИУ - филиал PAНХ и ГС. Т. 8. Выпуск 1 (28). С. 66-74.

[3] Бранский В.П., Микайлова И.Г., Зобова М.Р. Проблема «смысла жизни»: общефилософское и общенаучное значение / Бранский В.П., Микайлова И.Г., Зобова М.Р. СПб.: Изд-во СПбГЭУ, 2017. 83 с.

[4] Галкин Д.В. Техно-художественные гибриды, или искусство, политика и цифровые технологии в культурной динамике второй половины XX века // Гуманитарная информатика. 2008. Вып. 4. С. 50-75.

[5] Галкин Д.В. Digital Culture: методологические вопросы исследования культурной динамики от цифровых автоматов до техно-био-тварей // Международный журнал исследований культуры. 2012. № 3 (8). C. 11-16. URL: //www.culturalresearch.ru (дата обращения: 20.04.2018).

[6] Гир Ч. Цифровая контркультура / Пер. с англ. Д. В. Галкина. URL: // http://docplayer.ru/29837976Cifrovaya-kontrkultura-charli-gir-perevod-d-galkina.html \#show_full_text (дата обращения: 20.04.2018).

International Culture \& Technology Studies, Vol. 3, No. 3 
[7] Добринская Д.Е. Социологическое осмысление Интернета: теоретические подходы к исследованию сети // Вестник Московского ун-та. Сер. 18. Социология и политология. 2016. № 3. С. 21-37.

[8] Ерохин С.В. Эстетика цифрового компьютерного изобразительного искусства: автореф. дисс. д-ра филос. наук: 09.00.04. М., 2010.

[9] Журавлева Е.Ю. Современные модели развития гуманитарных наук в цифровой среде // Вопросы философии. 2011. № 5. С. 91-98.

[10]Казаков М.Ю., Кутырев В.А. Интернет как сетевая публичная сфера // Современные проблемы науки и образования. - 2013. - № 3. URL: http://www.science-education.ru/ru/article/view?id=9328 (дата обращения: 27.12.2018).

[11]Кастельс М. Становление общества сетевых структур. Новая постиндустриальная волна на Западе: антология / под ред. В. М. Иноземцева. М.: Akademia, 1999. С. 494-505.

[12]Кириченко Е.И. Цифровое искусство: способ коммуникации или средство новой художественной образности? // URL: https://elibrary.ru/download/elibrary_32475542_45386636.pdf (дата доступа 2.05.2018).

[13]Кулешов В.В. Роль автора в цифровом искусстве // Декоративное искусство и предметнопространственная среда. Вестник МГХПА. 2015. № 3. С. 349-358.

[14]Медведева Т.Б. Технологическая утопия и формы ее репрезентации в современной культуре: прогрессивизм, трансгуманизм и цифровая утопия // Научные ведомости БГУ. Сер.: Философия. Социология. Право. 2011. № 20 (115). Выпуск 18. С. 55-61.

[15]Прокудин Д.Е., Соколов Е.Г. «Цифровая культура» vs «аналоговая культура» // Вестник СПбГУ. Сер. 17. 2013. Выпуск 4. С. 83-91.

[16]Соколова Н.Л. Цифровая культура или культура в цифровую эпоху?// Международный журнал исследований культуры/ 2012. № 3 (8). С. 6-10. URL: //www.culturalresearch.ru (дата доступа - 3.04.2018).

[17] Уилсон Р. Космический триггер / Пер. с англ., Киев: Изд-во «Янус», 2000. 304 с.

[18]Хоружий С.С. Постчеловек, Виртуальный человек и их социум // Постчеловек и постчеловечество: будущее цивилизации или её конец? (круглый стол)/Хоружий С.С., Фишман Л.Г., Комлева Н.А., Манойло А.В., Багдасарян В.Э., Радиков И.В., Федорченко С.Н., Абрамов А.В.// Вестник Московского гос. обл. ун-та (Эл. журнал). 2016. № 3. URL: https://evestnik-mgou.ru/ru /Articles/View/757 (дата доступа - 3.09.2018).

[19]Щекотихина А.В. Сетевые коммуникации в социальном пространстве киберкультуры // Философские и культурологические аспекты современного социально-гуманитарного и научно-технического знания. Курск: Некоммерческое партнерство «Академия методического и технического содействия экспертной деятельности», 2014. № 1. Раздел 2. С.30-32.

[20] Яковлев Л.С. Цифровые технологии в контексте антропологической революции Международный журнал исследований культуры/ 2012. № 3 (8). С. 52-61. URL: //www.culturalresearch.ru (дата доступа 12.05. 2018).

[21] Atkin, R. (1981). Multidimentional Man. Harmonds Worth: Penguine Books. 198 p.

[22] Barney, D. The Network society. Cambridge, 2004. Available at: http: //read.amazon.com//asin=B00CFHYPYS (accessed date: 10/12/2018).

[23] Castells, M. (2010). The Information Age: Economy, Society, and Culture /M. Castells. Blackwell Publishers. 2-nd. ed. John Wiley \& Sons Ltd, V. 3. 488 p.

[24] Kaku, M. (2011). Physics of the Future : How Science Will Shape Human Destiny and our Daily Lives by the Year 2100 / M. Kaku. 1st ed. New-York, London, Toronto: Doubleday. 542 p.

[25] Van Dijk J. (2006). The Network Society. Social Aspects of New Media. London. 304 p.

\title{
Digital Culture in the Network Society: Socio-Philosophical Analysis
}

\author{
E.E. Yelkina
}

\author{
ITMO University, Russia
}

\begin{abstract}
The article is devoted to social-philosophical analysis of the network society formation and the role of digital culture as a normative-ethical regulator of social relations in the context of globalization and virtualization of social communications. The transition of the information society to the network society is explained as a result of the digital revolution, the development of the Internet and NBICS-converging technologies. Together they are shaping the information infrastructure of the network society, conducive to virtualization of social communications. The positive and negative factors of the influence of globalizing social network communications on the formation of a new social order are regarded. The issues of decentralization of power, formation of digital culture models
\end{abstract}


and practices are investigated. The paper represents the analysis of concepts and the basic approaches to digital culture research. The problem of the principles and means appropriate to integrate practices of digital culture and traditional forms of culture is discussed in the paper as a condition of social system stability in the development of the network society.

Keywords: network society; the Internet, information and communication technologies, virtual reality, digitisation, digital culture, transformation of values

\section{References}

[1] Alekseev A.Ju. (2014). Kognitivno-antropologicheskie problemy issledovanija jelektronnoj kul'tury [Epistemological and anthropological problem of e-culture research] // "Vestnik gumanitarnogo fakul'teta IGHTU”. [Proc. “Bulletin of the Faculty of Humanities ISChTU”]. No. 7. P. 35-40.

[2] Balajan A.A., Tomin L.V. Sovremennye diskussii o setevyh organizacijah i setevom vzaimodejstvii. Metodologija analiza i problemy prakticheskogo primenenija [Modern discussion about network organizations and network interaction]// "Nauchnye trudy SZIU" - filial RANH i GS. ["Scientific notes of NWIG RANE SS"]. Vol. 8. No. 1 (28). P. 66-74.

[3] Branskij V.P., Mikajlova I.G., Zobova M.R. (2017) Problema «smysla zhizni»: obshhefilosofskoe i obshhenauchnoe znachenie [The problem of "the sense of life": the common philosophical and scientific meaning]. / Branskij V.P., Mikajlova I.G., Zobova M.R. SPb.: Publ. SPbSEU. 83 p.

[4] Galkin D.V. (2008).Tehno-hudozhestvennye gibridy, ili iskusstvo, politika i cifrovye tehnologii v kul'turnoj dinamike vtoroj poloviny XX veka [Techno-art hybrids or art, politics, \& digital technologies in cultural dynamics of the second half of the XXth century] // "Gumanitarnaja informatika" [Proc. "Humanitarian Informatics"']. No 4. P. 50-75.

[5] Galkin D.V. (2012). Digital Culture: metodologicheskie voprosy issledovanija kul'turnoj dinamiki ot cifrovyh avtomatov do tehno-bio-tvarej. [Digital Culture: methodological issues of cultural dynamics research from digital automats to techno-bio-species] // "Mezhdunarodnyj zhurnal issledovanij kul'tury". [Proc. "International journal of cultural research”]. No 3 (8). P. 11-16. Available at: //www.culturalresearch.ru (accessed date: 20/04/2018).

[6] Gir Ch. Cifrovaja kontrkul'tura [Digital contr-culture]. /Trans. From Eng. D.V. Galkin. Available at: // http://docplayer.ru/29837976-Cifrovaya-kontrkultura-charli-gir-perevod-d-galkina.html\#show_full_text (accessed date: 20.04.2018).

[7] Dobrinskaja D.E. (2016). Sociologicheskoe osmyslenie Interneta: teoreticheskie podhody k issledovaniju seti [Sociological reflection of the Internet: theoretical approach to the network research]. // "Vestnik Moskovskogo un-ta". Ser. 18. "Sociologija i politologija”. [Proc. "Bulletin of the Moscow University" Ser. 18 "Sociology and Politology”]. No 3. P. 21-37.

[8] Erohin S.V. (2010). Jestetika cifrovogo komp'juternogo izobrazitel'nogo iskusstva [Ethtetics of digital computer fine art]: avtoref. dis... d-ra filos. nauk [autoref. diss. Dr. of Ph]: 09.00.04. M.

[9] Zhuravleva E.Ju. (2011). Sovremennye modeli razvitija gumanitarnyh nauk v cifrovoj srede [Modern models of the Humanities development in digital environment]. // "Voprosy filosofii." [Proc. "Issues of Philosophy”]. No 5. P. 91-98.

[10] Kazakov M.Ju., Kutyrev V.A. ( 2013). Internet kak setevaja publichnaja sfera [Internet as a network public sphere]. // "Sovremennye problemy nauki i obrazovanija" [Proc. "Modern problems of science and organization”]. No 3. Available at: http://www.science-education.ru/ru/article/view?id=9328 (accessed date: 27/12/2018).

[11] Kastels M. (1999). Stanovlenie obshhestva setevyh struktur. Novaja postindustrial'naja volna na Zapade: antologija [The formation of netmork structures society. A new post-industrial wave on the West]. /Ed. V.M. Inozemceva. M.: Akademia. [Publ. Academy]. P. 494-505.

[12] Kirichenko E.I. Cifrovoe iskusstvo: sposob kommunikacii ili sredstvo novoj hudozhestvennoj obraznosti? [Digital art: the way of communication or new means of the fine artistic images]. // Available at: https://elibrary.ru/download/elibrary_32475542_45386636.pdf (accessed date 2/05/2018).

[13] Kuleshov V.V. (2015). Rol' avtora v cifrovom iskusstve [The autor's role in ditital art]. // "Dekorativnoe iskusstvo i predmetno-prostranstvennaja sreda. Vestnik MGHPA”. [Proc. "Decorative Art \& object-space environment. Bulletin MSHPA']. No 3. P. 349-358.

[14] Medvedeva T.B. (2011). Tehnologicheskaja utopija i formy ee reprezentacii $v$ sovremennoj kul'ture: progressivizm, transgumanizm i cifrovaja utopija [Technological utopia and the form of its representation in modern culture]. // "Nauchnye vedomosti BGU”. Serija: "Filosofija. Sociolonija. Pravo" [Scientific Bulletin of BSU” Ser.: "Phylosophy. Sociology. Science of Law”]. No. 20 (115). Issue 18. P. 55-61.

[15] Prokudin D.E., Sokolov E.G. (2013). «Cifrovaja kul'tura» vs «analogovaja kul'tura» ["Digital culture” vs "analog culture"]. // "Vestnik SPbGU” [Proc. "Bulletin of SPbSU”]. Ser. 17. Issue 4. P. 83-91. 
[16] Sokolova N.L.( 2012). Cifrovaja kul'tura ili kul'tura v cifrovuju jepohu? [Digital culture or culture in the digital age?] // "Mezhdunarodnyj zhurnal issledovanij kul'tury" [Proc. "International journal of cultural research"]. No. 3 (8). P. 6-10. Available at: //www.culturalresearch.ru (accessed date: 3/04/2018).

[17] Uilson R. (2000). Kosmicheskij trigger [Cosmic trigger]. /Trans. from Eng., Kiev: Publ.«Janus». 304 p.

[18] Horuzhij S.S. (2016). Postchelovek, Virtual'nyj chelovek i ih socium [Post-human, Vurtual humam and their society]. // "Postchelovek i postchelovechestvo: budushhee civilizacii ili ejo konec?" ["Post-human \& posthumanity: future or the end of civilization?" (kruglyj stol) ['round table'] / Horuzhij S.S., Fishman L.G., Komleva N.A., Manojlo A.V., Bagdasarjan V.Je., Radikov I.V., Fedorchenko S.N., Abramov A.V. // "Vestnik Moskovskogo gosudarstvennogo oblastnogo universiteta" (Jelektronnyj zhurnal). [Proc. "Bulletin of MSRU”] (on-line journal). No. 3. Available at: https://evestnik-mgou.ru/ru /Articles/View/757 (accessed date: 3/09/2018).

[19] Shhekotihina A.V. (2014). Setevye kommunikacii v social'nom prostranstve kiberkul'tury [Network communications in social space of cyber culture]. // "Filosofskie $i$ kul'turologicheskie aspekty sovremennogo social'no-gumanitarnogo i nauchno-tehnicheskogo znanija" [Proc. "Philosophical \& cultural aspects of modern social-humanitarian knowledge"]. Kursk: Nekommercheskoe partnerstvo «Akademija metodicheskogo i tehnicheskogo sodejstvija jekspertnoj dejatel'nosti» [Non-commercial partnership "Academy of methodological and technical assistance expertise"]. No. 1. Vol. 2. P.30-32.

[20] Jakovlev L.S. (2012). Cifrovye tehnologii v kontekste antropologicheskoj revoljucii [Digital technologies in the context of the anthropological revolution]. "Mezhdunarodnyj zhurnal issledovanij kul'tury" [Proc. "International journal of culture research"]. No. 3 (8). S. 52-61. Available at: //www.culturalresearch.ru (accessed date: 12/05/ 2018).

[21] Atkin R. (1981). Multidimentional Man. Harmonds Worth: Penguine Books. 198 p.

[22] Barney D. (2004).The Network society. Cambridge. Available at: http: //read.amazon.com//asin=B00SFHYPY (accessed date: 10/12/2018).

[23] Castells, M. (2010). The Information Age: Economy, Society, and Culture / M. Castells. Blackwell Publishers. 2-nd. ed. John Wiley \& Sons Ltd, V. 3. 488 p.

[24] Kaku, M. (2011). Physics of the Future : How Science Will Shape Human Destiny and our Daily Lives by the Year 2100 / M. Kaku. 1st ed. New-York, London, Toronto: Doubleday. 542 p.

[25] Van Dijk J. (2006). The Network Society. Social Aspects of New Media. London. 304 p. 